\title{
Actor Network Theory: a suitable framework to understand how land cover mapping projects develop?
}

\author{
Alexis Comber ${ }^{1 *}$, Peter Fisher ${ }^{1}$ and Richard Wadsworth ${ }^{2}$ \\ ${ }^{1}$ REVIGIS Project, \\ Department of Geography, \\ University of Leicester, \\ Leicester, LE1 7RH, UK \\ ${ }^{2}$ Centre for Ecology and Hydrology, \\ Monks Wood, \\ Abbots Ripton, \\ Huntingdon, Cambs. UK
}

*Contact Author:

\begin{abstract}
The Countryside Surveys of 1990 and 2000 are introduced and their methodological or ontological differences described. Actor-Network Theory (ANT) examines the processes by which individual scientific claims are supported, debated and constructed by determining the interactions, connections and activities of the actors involved. The actors and their networks for the Countryside Surveys of 1990 and 2000 are compared. Such an analysis provides a description of why science evolves. Changes in the commissioning context behind scientific results and the process by which empirical facts are established are clearly illustrated. This type of analysis goes beyond the technological developments that would be revealed if only the scientific elements were examined. This type of analysis provides a useful tool to those seeking to reconcile ontological and semantic differences between scientific data.
\end{abstract}

Keywords: Countryside Survey; Actor-Network Theory.

\section{Introduction}

The real world is almost infinitely complex, fuzzy and dynamic. Geographic data is a sub-set of information that represents some features, attributes and objects of the world; typically it includes both physical (e.g. land cover, soil type) and socio-economic (e.g. land use, soil capability) facets. The manner in which features of the world are identified as being of interest (worthy and capable of being mapped), and organised varies from application-to-application, institutionto-institution and country-to-country. In this sense the measurement of geographic phenomena varies more than in many other disciplines and can be seen as strongly socially constructed; this demands an analytical approach that is context sensitive. Geographic data capture follows, more or less strictly, cartographic or database objectives, rules and criteria concerned with where something is (delineation) and what it is (identification). Mapping land cover proceeds by classifying what types of cover exist and dividing the world into discrete but strictly contiguous objects. This generic issue of deciding what to delineate and identify is common to many environmental mapping programmes and is explored here with reference to recent land cover mapping initiatives in the UK.

The underlying ontology, or specification of a conceptualisation (Gruber, 1993), of any land cover survey reflects a particular set of mapping paradigms deemed 
to be suitable for the task in hand. The origins of this specification depend upon the scientific and cultural norms of the agency, institution or organisation responsible for the data. Every ontology defines which objects are identified, the intended meaning behind object labels or nomenclatures, and the characteristics of the database structures: timing, periodicity, scale and granularity of data recording and information reporting. For example, Harvey \& Chrisman (1998) show how different agencies construct different notions of "Wetlands" in order to manage different policy objectives for the same area, and Bowker (2000) showed the extent to which biodiversity data is deeply constructed by "historiographical issues" and institutional politics. More general effects of institutional and cultural context upon geographic information have been considered with reference to Geographical Information Systems (GIS). Anderson (1996) proposes an approach to GIS evaluation that considers the transfer of technology in the light of organisational context. Martin (1998) suggests that prominent issues in the development of GIS should be considered in their evaluation. Visser et al. (2001) argue for the development of "semantic translators" to surmount the differences in ontology (conceptualisation) in geographic data. This body of work has shown that considering both the technical and the organisational components of geographic information enables a greater understanding of its suitability for other applications. Analysis of the interactions between these aspects will provide a greater understanding of how the land cover information was derived and what it means.

The notions of interoperability and transferability of data are increasingly important (Bishr, 1998; Visser et al., 2001). Current approaches to the evaluation of land cover monitoring activities focus almost exclusively on technical aspects: the distribution and number of the sample, the extent of correspondence with a validation dataset, dataset consistency, and so on. They do not provide a framework within which it is possible to critique the glasses through which we view the world. We argue that technological developments on their own are not sufficient to be able to understand, evaluate and relate geographical data with different ontological pedigrees; such data have to be viewed in the context of their conceptualisation and construction.

Actor-network theory (ANT) is associated with the analyses of scientific and technological artifacts by Bruno Latour and Michel Callon in the late 1980s. Whilst Latour has never referred to his own work as "Actor-Network Theory", the concepts were formalised into a theory by Callon and John Law. In studying science, technology and society (STS), Latour and Callon argue that scientific knowledge is local and constructed by a network of actors (Latour, 1987; Callon, 1991). Rather than considering the results or representations produced by science, ANT seeks to identify the processes that produce the results. Specifically it tries to circumvent any need to choose between internalist and externalist explanations of results. Internalism sees scientific activity purely resulting from the structure of its own discipline, whilst externalism explains scientific activity in terms of the political and historical context. In ANT everything is strategic, negotiated and contingent - there is no 'inside' or 'outside', simply networks and their connections. It has been of great interest to those involved in studying the creation of science, because it offers the opportunity to view the activity of scientific investigation, not just in terms of results and accuracy of result, but also process.

\subsection{Land cover mapping in the UK as a case study?}


The Countryside Survey of the United Kingdom is a monitoring programme that has quantified the extent of changes in the natural environment at irregular intervals since 1978 (Haines-Young et al., 2000). We are primarily concerned with the last two surveys (1990 and 2000) that report land cover through two components:

- Field Survey of broad habitats and landscape features (FS1990, FS2000);

- Land Cover Mapping from satellites (LCMGB and LCM2000)

Acronyms for the different component datasets are given in Table 1.

Table $1 \mathrm{~A}$ list of the acronyms used for different datasets

\begin{tabular}{|l|c|c|}
\hline Dataset & Acronym & Reference \\
\hline Satellite derived land cover map (generic) & LCM & N/A \\
\hline Field Survey (generic) & FS & N/A \\
\hline Land Cover Map of Great Britain (1990) & LCMGB & Fuller et al., 1994 \\
\hline Field Survey component of CS1990 & FS1990 & Barr et al., 1993 \\
\hline Land Cover Map 2000 & LCM2000 & Fuller et al., 2002 \\
\hline Field Survey component of CS2000 & FS2000 & Haines-Young et al., 2000 \\
\hline
\end{tabular}

LCM2000 and FS2000 are parallel components to those of the previous Countryside Survey in 1990 (CS1990) (Barr et al., 1993), but to different degrees both have changed their methodology, in terms of both delineation and identification. Such ontological differences are a generic problem in many environmental inventories and can be described in terms of the interactions of actors involved in commissioning, producing and using the data. Applying ANT to the Countryside Survey problem provides an illustrative explanation of the process by which the science and the products changed. We also show how such an analysis may be used to help:

- Users seeking to reconcile ontological and semantic differences between CS1990 and CS2000 in order to better understand the data;

- Researchers seeking to quantify and to provide formalisms to overcome these differences.

This paper proceeds by outlining some of the issues involved in the field and satellite surveys of CS1990 and CS2000 ( 2) a brief introduction to ANT ( 3), the application of ANT to Countryside Survey ( 4). The benefits of applying this analysis are discussed $(\sim 5)$, followed by some conclusions about the application of ANT ( 6).

\section{Countryside Survey 1990 and 2000}

The Countryside Survey is a series of surveys primarily funded by Government through the DoE, (Department of the Environment) which then became DETR (Department of Environment Transport and the Regions), and is currently DEFRA (Department of Environment, Food and Rural Affairs). The first survey was in 1978 and was based on a stratified random sample of 2561 kilometre squares (Bunce \& Heal, 1984). The stratification divided Great Britain into 32 land classes using a divisive multivariate statistical technique called TWINSPAN (Hill, 1979). Squares were selected at random from rural areas in each class and field surveyors recorded attributes of floristic and landscape features by annotating paper maps. This process was repeated in 1984 and 1990 and 1998. In 1978 the emphasis of the survey was on recording ecological data, especially vegetation and soils. In 1984 the survey focussed on the mapping of land cover and landscape features. In 1990, all the features of the previous surveys were recorded including all plant species present (with the help of an aide-memoir of 200 key species) and phyto-sociological associations. In 1998 existing squares were mapped for land cover changes rather than independently. The number of 
squares increased at each interval: 256 in 1978, 384 in 1984, 508 in 1990 and 569 in 1998. In 1990 and in 1998 the field survey data was complemented by a national land cover survey derived from the classification of satellite data.

\subsection{Countryside Survey 1990}

CS1990 adopted a dual approach to land cover, complementing the detailed field survey of $5081 \mathrm{~km}^{2}$ sample squares (FS1990) with a national census produced from satellite data (LCMGB). The LCMGB was funded by the DoE and BNSC (the British National Space Centre) as a demonstration of the viability of satellite imagery. Both FS1990 and LCMGB were produced by CEH (the Centre for Ecology an Hydrology, then known as the Institute for Terrestrial Ecology, ITE). The surveys are described by Barr et al. (1993) and Fuller et al. (1994). The LCMGB was the first complete survey of the land cover of Great Britain to be mapped from satellite imagery. It was produced using a supervised maximum likelihood classification of Landsat Thematic Mapper data that had been resampled to a pixel size of $25 \times 25 \mathrm{~m}$. It records 25 "Target" land cover types.

By combining the field survey and land cover map data, CS1990 sought to complement the information of each of the two land cover initiatives. But FS1990 and LCMGB were not conceived, designed nor implemented together. Rather they had different ontologies in terms of the granularity of the information they captured and the knowledge they embodied. Consequently they provided different answers to questions about land cover and this created problems when their results were compared. For instance, the satellite-derived LCMGB recorded the area of the key cover type "Open shrub heath / moor" as $8 \%$ of the country, while the field survey identified 5\% (Fuller et al., 1998: Table 7, p.113). The different ontological pedigrees of the data are further illustrated by Wyatt et al. (1993) who note discrepancies due to "differences in class definition and in the way the nomenclature was interpreted in the two surveys", and cite Bog as an example. In the 1990 field survey upland peat bog was defined from a botanical perspective, including wet ericaceous, predominantly heather moorland. LCMGB used a hydrological definition, which created a class of distinct spectral properties. Therefore the national extents of the two surveys differ greatly: $16,600 \mathrm{~km}^{2}$ (field survey), and $4300 \mathrm{~km}^{2}$ (LCMGB) (Fuller et al., 1998).

Despite the fact that the two surveys record fundamentally different things at different scales, with different nomenclatures, much of the work describing how the satellite data relate to the field survey data concentrated on describing the origins of difference between them (see for example, Wyatt et al., 1993; Cherrill et al., 1995; Fuller et al., 1998). The origins of difference were consistently identified as being:

- timing (growth cycles, seasonal differences, diurnal effects);

- spatial extent (the scale of data capture, geo-registration of satellite imagery, within-class heterogeneity, mixed pixels at boundaries);

- statistical issues (non-random collection of training data, poor repeatability of field surveys);

- issues of perception (choice of class labels, their definitions (nomenclature), methods of class recognition by surveyors, and the spectral separability of classes).

Presenting FS1990 and LCMGB as part of a "grand scheme", the focus was on the problems of integration rather than the opportunities presented by the different results. Each approach has its own advantages and disadvantages: the LCMGB can be used to provide national estimates / environmental audits as 
well as giving the broad context, and the FS1990 to provide highly detailed local estimates of land stock quality. Instead ontological differences were compounded by using the vector field-maps of the $1 \mathrm{~km}$ squares to provide the only estimate of the quality of LCMGB. The issue is not that the two surveys record different things but rather that the link between the two sets of features is inferred, and not rigorously defined.

The Scoping Study reports for the next Countryside Survey (Haines-Young \& Swanwick, 1996) recommended that the census of land cover using remotely sensed data be included as an integrated element of the CS2000 survey. The implication is that both projects were presented under the same "umbrella" in CS1990 for pragmatism and convenience.

\subsection{The Countryside Survey 2000}

The Countryside Survey was repeated in 1998 and results were reported in 2000/2001. Like CS1990 it includes two components recording land cover: a sample based field survey (FS2000) and a census land cover survey derived from satellite data, Land Cover Map 2000 (Fuller et al., 2002). A fundamental change from CS1990 was the requirement to report in terms of Broad Habitats. This was in order to meet UK policy obligations as a result of the UN Rio Declaration (Secretariat on the Convention on Biological Diversity, 2000) and the EU Habitats Directive (CEC, 1992). CS2000 was funded only after it demonstrated how its results would relate to the demands of these policies. ECOFACT (Bunce et al., 1999) formally established links between FS2000 and other field based approaches and classifications in the UK including: National Vegetation Classification (NVC), Phase I Habitat Survey and the Biodiversity Action Plan Broad Habitats. This work meant that FS2000 was able to speak the language of policy in its reporting of land cover features. There was no parallel work for the land cover map.

Due to the policy imperative CS2000 was required to use the Broad Habitats of the Biodiversity Action Plan, to be defined by the Joint Nature Conservancy Council (JNCC). The JNCC, however, had little experience of the different conceptualisations of land cover features held by different organisations. Because the JNCC did not publish official Broad Habitat definitions until July 2000 (Jackson, 2000), the FS2000 and the LCM2000 teams had to apply working definitions. Furthermore, the Joint Nature Conservancy Council changed some of the working definitions. According to some of the field surveyors this created some confusion: field surveyors had their own understanding of the terminology and had difficulties in recognising differences in meaning of the same terminology.

\subsection{Field Survey 2000}

The FS2000 differs from FS1990 in:

- Extra squares to address issues raised by Scottish devolution;

- Only mapping apparent changes in the existing squares;

- Reporting changes in terms of Broad Habitats.

The devolved Scottish Parliament required results that related to Scotland. Extra sampling was needed because sampling ignored political boundaries and related only to the observed environment. In the unenclosed upland areas there was a further change in the 1990 methodology: for FS2000 only changes at the Broad Habitat level were mapped. This was to avoid the problem of interpreter variation that happens when independent estimates of land cover features are compared. Much apparent "change" can be the result of variation between 
different interpretations (Cherrill \& McClean, 1999a, 1999b). Financial constraints may have been a factor in this aspect of the revised methodology "Time saved in this reduced mapping methodology will be put to establishing extra plots" (Barr, 2001: section 8.15).

The recording only of change (and not the data primitives) assumes that the broad habitats will still be the currency of reporting land cover information for any future Countryside Survey, and provides a bias against reporting (what may be fatuous) change. This undermines the value of the field survey method that has recorded plant species and vegetation data consistently over time, allowing historical data to be re-analysed with respect to changed reporting frameworks (such as Broad Habitats in 2000).

\subsection{Land Cover Map 2000}

LCM2000 represents a significant methodological change from the past. It combines a parcel-based classification with some ancillary geographical data to provide greater classification accuracy and increased thematic detail. The major departures from LCMGB are:

- Vector rather than raster format;

- Per-parcel classification rather than per-pixel;

- An expanded attribute table;

- Changes in the reporting of land cover information.

Image segmentation algorithms were used to identify homogenous areas within composite satellite images which were classified using a maximum likelihood algorithm. Various knowledge-based correction procedures were applied to the classified data to correct those that had been classified out of context or identified with low confidence. These corrections were recorded and included in the parcel attributes allowing the application of corrections to be traced. LCM2000 identifies 16 Target classes, subdivided in 26 Subclasses corresponding to Broad Habitats.

The reasons for the change in methodology can be mainly attributed to three factors. Firstly, methodological advances such as parcel based approaches were developed through the CLEVER-Mapping project (Smith \& Fuller, 2001). Secondly, increased policy pressures (in response to international agreements) as exercised by environmental agencies, that were now responsible for management of habitats. The third factor was pressure from the requirements of the user community, some of whom perceived the LCMGB to have low accuracy due to their poor understanding of remote sensing issues. This pressure was evident in environmental agency representation on the LCM2000 Steering Committee. This meant that the LCM2000 methodology and specification had to directly assist the environmental agencies in fulfilling their statutory obligations.

\section{Actor-Network Theory}

ANT examines the processes by which individual scientific claims are supported, debated and constructed. By deconstructing and examining science, Latour (1987) observed that he often came across "black boxes", that is, scientific theories, facts or equipment that are taken for granted and accepted as being true, accurate and useful by the scientific community. To fully understand science Latour believes that we should examine the processes by which hypotheses are generated, how support for them are gathered, and how through further efforts as well as scientific endeavour such hypotheses later become "fact". Such facts in turn become the next layer of black boxes, or established truths. Latour uses a number of scientific stories or histories to illustrate how in the evolution towards 
a (now accepted) truth, there are various points at which the dissenting voice can intervene. A particular set of black boxes and paradigms exist, depending on where the point of entry is into the debate (Miettinen, 2001).

Latour emphasised the importance of rhetoric in determining or stabilising (Miettinen, 2001) the outcome of a scientific debate. Proponents of a particular theory try to get as much support as they can. As science normally progresses by extending existing scientific theories, so at each stage towards the acceptance of a hypothesis as a black box the support multiplies. The more black boxes and allies a theory has on its side, the harder it is to argue against: each objection will eventually come up against a black box that itself is almost impossible to argue against (given the support). The same network of allies and support also applies to laboratories and other research institutions

ANT proposes that ideas and theories compete with each other. For a new theory to be successful, it needs to gain allies and evidence of its own. It also needs to try to convert the allies of competitor theories for its own use. If the proponents of a new theory fail to gather a large enough network of allies then, in the long run, it will be unsuccessful. In this way ANT sees the connections between allied actors (scientists, theories, black boxes) as a network. The relationships in actornetwork mechanisms create a supporting feedback loop: Theory $A$ gains support from Theory $B$. At some point Theory $A$ becomes successful, and this success in turn offers further support to Theory $B$.

Latour's actor-network model is not about how scientists make discoveries; it is about how the truth is constructed from the statements that scientists make. ANT, with its models of networks is useful when confronted with the increasingly cross-disciplinary nature of science. If one accepts the notion that once a theory has enough support to become a black box, (that is, accepted as the truth until another truth emerges), then this has strong implications for rationality, objectivity and the status of science. Many reject Latour's model on this basis. ANT's theoretical richness derives from its refusal to reduce explanations to just natural, social, or discursive categories while recognizing the significance of each (Frohmann, 2001)

Seeking to explain and explore the social construction of GIS some workers have turned to ANT. Martin (1998) examined GIS implementation by analysis of the social and technical interactions involved; Martin (2000) demonstrated the utility of ANT for providing explanations of why similar GIS implementations produce different outcomes. Another corpus of work has investigated the process of negotiation over boundary objects. Understanding the dynamics of the negotiation process is a part of Latour's (1987) methodology of following scientists and tracing networks. These negotiations can lead to the adoption of definitions or some stability in procedures for GIS implementation. Harvey (1997) and Harvey \& Chrisman (1998) demonstrated the utility of boundary objects in assessing the relationships between GIS technology and peopleTheir approach involves more . han just the identification of boundary objects; it examines people's opinions and their relation to the boundary object in question, to ascertain differences in perceptions of the boundary object across social groups. Their examples, wetland classifications and technical standards, illustrate disagreement and localised utilisation of entity definitions or procedures that are meant to facilitate consistency across institutions and systems.

\subsection{Application of ANT}


The literature on ANT contains many concepts but their interpretation and application vary. Describing the concepts involved in ANT with the terms 'actor', 'network' and 'theory' is not straightforward. Martin (1998; 2000) provides a description of the concepts of ANT that focus on their potential use for the investigation of GIS actor-networks and the direction from which actornetwork analysis might approach geographic information. There are four aspects to applying ANT to a geographic domain: we need to identify: a) the actors, b) their networks, c) how ANT develops its analysis, and d) how ANT is applied. These are detailed in the following paragraphs.

A network is often described in terms of nodes and links. In ANT the nodes are Actors, and an Actor is any entity that interacts with other actors or serves as an intermediary between actors. ANT accepts humans and non-humans (objects) as actors, since all interactions between humans are mediated through objects of one type or another (Law, 1992). In ANT the links are the interactions between actors sometimes termed the "translations" (Latour, 1987). The translation between humans and objects occurs when an object is designed or used. Latour refers to this as the 'exchange of properties' between humans and non-humans. Interactions between actors are the primary building blocks of ANT but it has a number of more subtle relationships including: "boundary objects", "centres of calculation" (analytical positions of greater understanding), "inscription devices" (that record and therefore translate), and "obligatory point of passage" (a node that acts as an intermediary between networks) (Martin, 2000).

\subsection{The development of ANT}

The approach is to determine the interactions, connections and activities of actors involved. Even for small activities the possible number and dimension of all potential interactions (from strong to weak) of actors (human and non-human) at any particular point in time (as networks evolve) is very large.

To help impose some constraints, Callon (1991) and Martin (2000) identified the main types of intermediaries in scientific networks. The application of ANT involves deciding on the point of entry into the analysis. One way is to examine what the texts, information, and job titles say about the way that the actors are linked to form a network. The "official" information in mission statements, reports, product information can then be combined with how individuals describe their role and the roles of others. The analyst seeking to understand the process by which a product has come into being, needs information from a number of sources:

- Texts: especially how network associations are strengthened through citations and references. (Texts also includes information in graphs, diagrams, memos, database records and progress reports).

- Technical artefacts: especially how these align networks by dictating the resources required for an object to function. This may include the formal links between institutions and universities that legitimise activity giving strong academic associations.

- Human beings: and the relationships derived from position, job, responsibility, and peer evaluation. This includes the control and power relationships that shape the nature of actor interactions and the key individuals in the process. Who is the champion of the project and how do they interact with others actors? 
- Money: gets translated into actions, who is commissioning and paying for the project, who is assessing the validity of the end-product and how do these actors relate?

The links between actors have to be mapped in order to be able to elucidate the networks and structures. This can be done in many ways, but the key is to ensure that the dynamics of the actor-networks are adequately represented. Martin (2000) used two-dimensional network diagrams, placing the actors in one of three categories: "Input Resources", "Accountable Actors" and "Recipients". Links between the actors were based on notions of "Control", "Skills / Abilities", "Money", and "Information" to show the nature of their networks.

\section{Applying ANT to the Countryside Survey Land Cover Data}

The networks of the four land cover products were uncovered through an analysis of the published literature, internal reports, commissioning and scoping studies, and interim reports from the steering group. These were augmented by interviews with scientists, civil servants, agency representatives, current and future users. From this information ANT diagrams were produced using the structural framework developed by Martin (2000).

\subsection{ANT and LCMGB}

The actors and their linkages to LCMGB are shown in Figure 1. The uncluttered dynamics clearly show the initiative was a demonstration of what could be achieved with the latest technology. The DoE and BNSC commissioned and paid for the project, the raw data was in the form of satellite imagery, and the method was by existing per-pixel classification techniques drawing on the skills of the remote sensing community. These were brought together by the Earth Observation Section of CEH to produce the LCMGB. The impact of the field survey against which LCMGB was validated is clear: it exercised a degree of control over the final product and contributed information about the extent to which the classes described by LCMGB related to other more botanically orientated classifications. It must be pointed out that this "control" was only exercised post hoc.

\subsection{ANT and LCM2000}

The actors and their linkages in LCM2000 are shown in Figure 2. This exercise took place within a different context and with different actors to LCMGB. As a result the network and the nature of the influence between actors and over the project is different. The context within which actors formed networks changed and these differences can be seen in the way that LCM2000 was implemented. For example, instead of drawing on established methods, the EO Section at CEH entered into collaboration with a commercial organisation (Laserscan plc) to develop a completely new methodology for classifying satellite imagery. The LCM2000 speaks to a different audience than LCMGB. Compared to LCMGB, it was commissioned in a different way, applies a different methodology and reports different things. A key and new actor in the network is the Steering Group, primarily drawn from agencies and users of the LCMGB.

\subsection{ANT of FS1990}

The actors and their linkages for FS1990 are shown in Figure 3. The scenario for the FS1990 is uncluttered and the spheres of influence are very similar to those for LCMGB. The field survey had its origins firmly rooted in the development and expansion of previous surveys that had taken place in 1978 and in 1984. The "Previous Field Survey Methodology" therefore represents a stable influence on the whole process. It generates both skills for use in FS1990 as well as exercising 
some control. Similarly the Users contributing money to the 1990 exercise have little influence on the scientific method.

\subsection{ANT of FS2000}

The actors and their network for FS2000 are shown in Figure 4. The picture for FS2000 is much more complex than for FS1990. This is due to the increased number of actors exerting influence in many directions across the network. Of note are the impact of policy, the scoping study (Haines Young and Swanwick, 2000), and the ECOFACT (Bunce et al., 1999) work, and the influence of users on methodology, and the more central role of the methodology. The previous field survey is much less of a direct actor than in 1990, reflecting the shift in emphasis towards the satisfying the demands of policy rather than "science" per se.

\section{Discussion}

Before discussing the differences between the four networks two questions need to be asked: "Are these networks informative?" and "Are the networks defensible?" It is inevitable that the different actors will have different views as to how crucial their role was in the process and how the interactions between actors was manifested. It is also inevitable that not all actors and activities can be included (in fact beyond a certain level of complexity the diagrams cease to be interpretable and hence to supply information). We believe that these diagrams are informative and that they do encapsulate the issues around the commissioning and production of the land cover products. We also believe that the networks are defensible in that the actors and linkages that we portray can be deduced from the documentary evidence and links are limited to organisational control, money, skills and information: all factors that are relatively easy to identify.

The value of ANT is that it now allows us to compare CS1990 and CS2000 as presented in the Figures and to identify specific and general points.

5.1 LCMGB and LCM2000 (Figure 1 and Figure 2)

LCMGB was very much a scientific exercise; in 2000 there is a marked increase in the complexity of the network and the influence of various actors. The overriding themes are: the increased influence of policy, consultation with previous and future users and their influence over the new methodology. In 1990 the steering group is not a significant actor but in LCM2000 it was much more active as a forum for decision-making. Potentially differing interests among the users were mediated through the concept of Broad Habitats, which are represented here as part of the 2000 Methodology. A noteworthy similarity is that the field survey still provides the only measures of data quality for the LCM2000 product.

Compared to LCMGB there are more significant actors in LCM2000: the role of the Earth Observation Section is less central, the Methodology and the Steering Group are more central, LCMGB becomes an actor while satellite imagery is no longer part of the network of actors. (One of the aims of LCMGB was to demonstrate the utility of satellite imagery for mapping land cover, hence its depiction as an actor in 1990. By the time of commissioning LCM2000, acceptance of the paradigm of land cover mapping from satellite imagery is sufficiently widespread for its use to be uncontroversial and whilst it is still an actor it is not a central one and for clarity has been omitted from the diagram.) The links between actors in 2000 is more complex: money is coming from more sources requiring greater accountability, policy has a strong influence, users 
influence the Methodology, formal control is far more prevalent, there is greater Information exchange between actors.

By comparing the differences between the two figures (1 and 2) we can easily see the different drivers and pressures coming to play in the production of LCM2000. The actors represented in the network are the main ones, it does not show or consider the role of other actors such as the notion of acceptable accuracy, nor of individual people who may have exerted influence such as Profs Roy Haines-Young (University of Nottingham) and Mike Roberts (Director of ITE/CEH).

\subsection{LCMGB and FS1990 (Figure 1 and Figure 3)}

There are many similarities between the actor-networks of FS1990 and LCMGB. The raw data, satellite imagery and field data, and established scientific methodology are significant actors for both projects. They differ in the strength of the previous methodology and in the control exercised over the LCMGB results by FS1990 through the validation process.

\subsection{LCM2000 and FS2000 (Figure 2 and Figure 4)}

The increased influence of policy and the users over the final land cover product is in evidence for both LCM2000 and FS2000, increasing the number of actors and new methodologies. The influence of previous methodologies is stronger in the FS2000 network, as the changes in methodology were small relative to the dramatic changes in the land cover map methodology. ECOFACT makes a clear link between FS2000 and Policy, whilst in LCM2000, this link is more diffuse, running through the Agencies / Users, the LCM2000 Steering Group and the new methodology to the final LCM2000 product.

\subsection{FS1990 and FS2000 (Figure 3 and Figure 4)}

The major differences are the increased influence of Policy and the role of the Scoping Report (Haines-Young and Swanwick, 2000) to address the policy issues. Here the Scoping Report is the link between the government and the producers of FS2000. In 2000 there is much less of a link between scientific practice, as represented by "Ecological Science" and "Previous field survey Methodology" in 1990. Instead, the influence of policy and user demands comes together with FS1990 Methodology in the tweaked FS2000 methodology.

From this comparison of the two field surveys (Figures 3 and 4) it can be seen that the context within which the field survey was conducted had also changed significantly. The methodology from previous surveys is no longer an accountable actor, rather it can be seen as a legacy informing current practice. The DEFRA relationship with CEH is much less direct in the 2000 survey, reflecting the increased political role and statutory responsibility of the environmental agencies.

\subsection{General Points}

Using ANT to characterise the Countryside Surveys 1990 and 2000 and the way they were commissioned is revealing. It clearly illustrates the changed political world within which science is commissioned: direct links to government are weaker as responsibility for different spheres of interest (such environmental monitoring) is decentralised away from the various ministries into independent agencies.

In CS1990 the scientists determined the reporting categories for the field survey and the land cover map and identified the scientific questions that could be answered by the data. Necessarily this was robust science, developing and extending an existing methodology. In CS2000 dialogue with stakeholders 
started early and their role was formalised through a steering group, the Scoping report (Haines-Young \& Swanwick 2000) and work such as ECOFACT (Bunce et al., 1999). This led to an enlarged user community (and funders) it also increased the number of (potentially) conflicting objectives. Information to meet the needs of Government and International policies increased dramatically between the two dates. For CS2000 the users were consulted before, during and after production of land cover information, they were also allowed to inform, guide and control the methodology used. The Scoping Study (Haines-Young and Swanwick, 2000) was able to present a case for the commissioning of CS2000 whilst advising the government on what questions it was possible to answer. This reflects the changed political world (devolved responsibility in the hands of the agencies) and the influence of international legislation and agreements-actors not directly included in this analysis. These two factors have combined to significantly change the questions for which answers are being sought by initiatives like the Countryside Survey. The degree to which these additional requirements have and could be met is still an open question.

In this analysis we applied the structural framework developed by Martin (2000) to illustrate the actors and the networks of conservation bodies in Ecuador. Martin examined the different networks in Ecuador by the flows of money, control, information and skills. We have shown this approach to be relevant for a comparison of the CS1990 and CS2000 networks and a useful method for describing their different scientific and policy contexts. This validates the descriptive potential Martin's approach and indicates its applicability to other land use policy arenas in the UK or internationally. It builds on the work of Harvey and Chrisman (1998) who considered the different ways that wetlands were constructed by different agencies as well as that of Martin (2000).

Another theme that emerges from this analysis is the acceptance of measures of remotely sensed land cover map quality through correspondence with a field survey. After CS1990 there was much work examining differences between the field and satellite data and the specific integration problems (nomenclatures, timing, spatial and statistical) described in Section 2. Overcoming these problems formed the basis of the recommendations for the future Countryside Survey update in 1998-2000 (CS2000). It is interesting to note that Fuller et al. (1998) commented on the complex interactions between scale and resolution of the data and for cartography at different scales: "there is likely to be inconsistency if one is used to validate the other" (Fuller et al., 1998: p123). Such inconsistency is inevitable. Further, they conclude their paper by stating: "A planned update in 1998-2000 will address many of the problems of the Countryside Survey 1990, upgrade the detail and accuracy and will ensure even closer integration between the field and satellite surveys" (Fuller et al., 1998: p125). Unfortunately, the methodological differences were not fully resolved in CS2000. However, in terms of ANT, the validation of the land cover map by the field survey in 2000 has gained the status of one of Latour's black boxes: it has become an accepted paradigm of data quality reporting.

We are aware that we have only documented the process of evolution from CS1990 to CS2000, reflecting our interest in how differences between field survey and satellite land cover might have been resolved. However the field survey component of the Countryside Survey series has a much longer and varied history. A more specific analysis of the evolution of the fields survey series may provide a revealing insight in to the way that scientific enquiry has changed: for 
instance, the move away from self-tasked initiatives by scientists to a situation where scientists are contractors. However, this would require access to information about the field surveys of 1978 and 1984 (texts, reports, minutes of meetings, personnel, etc.), and was beyond the scope of our specific interests.

A final criticism that may be levelled at this sort of analysis concerns the certainty with which a retrospective study adequately captures reality 10 years ago. Generally, scientific activity today seeks to make its results more responsive to the needs of society. Further, here in this work we have characterised the contexts for the CS1990 land cover mapping exercises by a stronger scientific influence and weaker policy influence than equivalent products today. The accusation of self-fulfilling scientific prophesy can be countered by considering a number of activities and legislation in the policy arena today that are concerned with land cover mapping. Ten years ago there were few, now there are many. There exists a wider consensus in society today about environmental issues compared to ten years ago: the (scientific) world is different. We document that as well as reflect it.

\section{Conclusions}

ANT approaches scientific endeavour from a sociological perspective. Networks describe people and institutions, artefacts and entities that have different spheres of influence including the design of the new technology, its diffusion and its operation. This type of analysis provides a frame with which to represent the individual and institutional views of those involved in commissioning a land cover mapping exercise. Applying Martin's (2000) schema to describe the commissioning the Countryside Surveys of 1990 and 2000 offers an interesting overview of the process. This is different than would be obtained if only the scientific elements were considered, as the networks described in this work contain actors who are not usually considered when scientific products are evaluated.

Changes in the context within which the two datasets were commissioned are clearly illustrated in this process: the network of actors and the nature of the influence they have over the final product are seen when their interlocking networks are drawn. ANT as model allows the detail of scientific debates to be examined, and shows actor-network theory able to incorporate evidence from a variety of sources.

The analysis of the differences in the networks describing CS1990 and CS2000 provides a useful tool to those seeking to reconcile ontological and semantic differences between the surveys. Understanding the origins of the datasets and their construction casts a light on the different questions that are being answered by the data both across time (1990 to 2000) and across different methodologies (field survey and satellite land cover map). In 1990 the field survey reported land cover stock in terms of 59 Reporting Classes and the Land Cover Map using 25 Target classes. In CS2000, they both report in terms of similarly defined Broad Habitats, which were only formalised by JNCC only months before the first results were announced.

ANT describes the various networks and allies involved in the creation and commissioning of science. It illustrates the workings behind the derivation of scientific results and the process by which empirical facts are established. ANT has proved to be useful tool for highlighting the specific differences that need to be addressed by any formal approach to reconciling data with different ontological pedigree. 


\section{Acknowledgements}

This paper would not have been possible without the co-operation of a number of those involved in commissioning and executing Countryside Survey 2000, including Robin Fuller, Geoff Smith, Andrew Stott, and Roy Haines-Young. This paper describes work done within the REVIGIS project funded by the European Commission, Project Number IST-1999-14189. We wish to thank our partners in the project, especially Andrew Frank, Robert Jeansoulin, Arko Lucieer, Alfred Stein, Nic Wilson, Mike Worboys and Barry Wyatt.

\section{References}

Anderson, C. S., 1996. GIS Development Process: A framework for considering the initiation, acquisition and incorporation of GIS technology. Journal of the Urban and Regional Information Systems Association 8(1), 10-26.

Barr, C.J., 2001. Countryside Survey 2000: Field Handbook Draft 3a. Institute of Terrestrial Ecology, unpublished.

Barr, C.J., Bunce, R.G.H., Clarke, R.T., Fuller, R.M., Furze, M.T., Gillespie, M.K., Groom, G.B., Hallam, C.J., Hornung, M., Howard, D.C., Ness, M.J., 1993.

Countryside Survey 1990: main report. Countryside 1990 Series: Volume 2. Department of the Environment, London.

Bishr, Y., 1998. Overcoming the semantic and other barriers to GIS interoperability. International Journal of Geographical Information Science 2(4), 299-314.

Bowker G.C. 2000. Mapping biodiversity. International Journal of Geographical Information Science 14 (8), 739-754.

Bunce, R. G. H., Barr, C. J., Gillespie, M. K., Howard, D. C., Scott, W. A., Smart, S. M., van de Poll, H. M., Watkins, J. W., 1999. ECOFACT 1 Vegetation of the British Countryside. London, HMSO.

Bunce, R.G.H., Heal, O.W., 1984. Landscape evaluation and the impact of changing land-use on the rural environment: the problem and an approach. In Roberts, R.D., Roberts, T.M. (Eds.), Planning and Ecology. Chapman Hall, London, pp. 164-188.

Callon, M., 1991. Techno-economic networks and irreversibility. In: Law, J. (Ed.), A Sociology of Monsters: Essays on Power, Technology and Domination. Routledge, London, pp. 132-161.

Cherrill, A., McClean, C., 1999a. Between-observer variation in the application of a standard method of habitat mapping by environmental consultants in the UK. Journal of Applied Ecology 36(6), 989-1008.

Cherrill, A., McClean, C., 1999b. The reliability of 'Phase 1' habitat mapping in the UK: the extent and types of observer bias. Landscape and Urban Planning 45(2-3), 131-143.

Cherrill, A.J., McClean, C., Fuller, R.M., 1995. A comparison of land cover types recognised in an ecological field survey of Northern England and in the first remotely sensed Land Cover Map of Great Britain. Biological Conservation 71, 313-323.

Commission of the European Communities, 1992. Council Directive 92/43/EEC of 21 May 1992 on the conservation of natural habitats and of wild fauna and flora, Official Journal of the European Communities, L206.

Frohmann, B., 2001. Taking information policy beyond information science: applying the actor network theory.

http://www.ualberta.ca/dept/slis/cais/frohmann.htm [available, 30/10/01]. 
Fuller, R.M., Groom, G.B., Jones, A.R., 1994. The Land Cover Map of Great Britain: an automated classification of Landsat Thematic Mapper data.

Photogrammetric Engineering and Remote Sensing 60, 553-562.

Fuller, R.M., Smith, G.M., Sanderson, J.M., Hill, R.A., Thomson, A.G., 2002. Land Cover Map 2000: construction of a parcel-based vector map from satellite images. The Cartographic Journal 30(1), 15-25.

Fuller, R.M., Wyatt, B.K., Barr, C.J., 1998. Countryside survey from ground and space: different perspectives, complementary results. Journal of Environmental Management 54(2), 101-126.

Gruber, T.R. 1993. A translation approach to portable ontology specifications. Knowledge Acquisition 5(2), 199-220.

Haines-Young, R.H., Swanwick, C., 1996. Scoping study for Countryside Survey 2000 (Part A) First Interim Report to Department of the Environment. University of Nottingham, Nottingham.

Haines-Young, R.H., Swanwick, C., 2000. Countryside Survey 2000: Scoping Study. University of Nottingham, Nottingham.

Harvey, F., 1997. Improving multi-purpose GIS design: Participative design. In: Hirtle S. C., Frank A. U. (Eds.), Spatial Information Theory: A theoretical Basis for GIS. Springer, Berlin, pp. 313-328.

Harvey, F., Chrisman, N., 1998. Boundary objects and the social construction of GIS technology. Environment and Planning A 30(9), 1683-1694.

Hill, M.O., 1979. TWINSPAN-A FORTRAN program for arranging multivariate data in an ordered two-way table by classification of the individual attributes. Department of Ecology and Systematics, Cornell University, Ithaca, New York.

Jackson, D.L., 2000. JNCC Report No. 307: Guidance on the interpretation of the Biodiversity Broad Habitat Classification (terrestrial and freshwater types): definitions and the relationships with other habitat classifications. Joint Nature Conservation Committee, Peterborough.

Latour, B., 1987. Science In Action. Harvard University Press, Cambridge. Law, J., 1992. Notes on the theory of the actor-network: ordering, strategy and heterogeneity. Systems Practice 5(4), 379-393.

Martin, E., 1998. GIS Implementation and the Un-Theory: Some useful concepts from ANT. http://students.washington.edu/ ewmartin/papers/ant511.htm [available 21/10/01]. Martin, E., 2000. Actor-networks and implementation: examples from conservation GIS in Ecuador. International Journal of Geographical Information Science 14(8), 715-737.

Miettinen, R., 2001. What is Actor-Network Theory? http://carbon.cudenver.edu/ mryder/itc/act_net_dff.html [available 30/10/01]. Secretariat on the Convention on Biological Diversity, 2000. Sustaining Life on Earth: How the Convention on Biological Diversity promotes nature and human well-being. http://www.biodiv.org/doc/publications/cbd-guide-en.pdf [available 13/10/01].

Smith, G.M., Fuller, R.M., 2001. An integrated approach to land cover classification: an example of the island of Jersey. International Journal of Remote Sensing 22(16), 3123-3142.

Swanwick, C., Dunn, R. 1996. Countryside Survey 1990: Policy Review. Countryside Survey Series No 9. DoE, London. 
Visser, U., Stuckenschmidt, H., Schuster, G., Vögele, T., 2001. Ontologies for geographic information processing. Computers and Geosciences 28 (1), 103-117 Wyatt, B.K., Greatorex-Davies, N.G., Bunce, R.G.H. Fuller, R.M., Hill, M.O., 1993. The comparison of land cover definitions. Countryside 1990 Series: Volume 3. Department of the Environment, London. 


\section{List of Figures}

Figure 1. Network of LCM1990 actors and their links. The nature of the links is indicated by the style of the line: money (dash-dot); control (dotted); information (dashed); skills (solid).

Figure 2. Network of LCM2000 actors and their links. The nature of the links is indicated by the style of the line: money (dash-dot); control (dotted); information (dashed); skills (solid).

Figure 3. Network of FS1990 actors and their links. The nature of the links is indicated by the style of the line: money (dash-dot); control (dotted); information (dashed); skills (solid).

Figure 4. Network of FS2000 actors and their links. The nature of the links is indicated by the style of the line: money (dash-dot); control (dotted); information (dashed); skills (solid). 


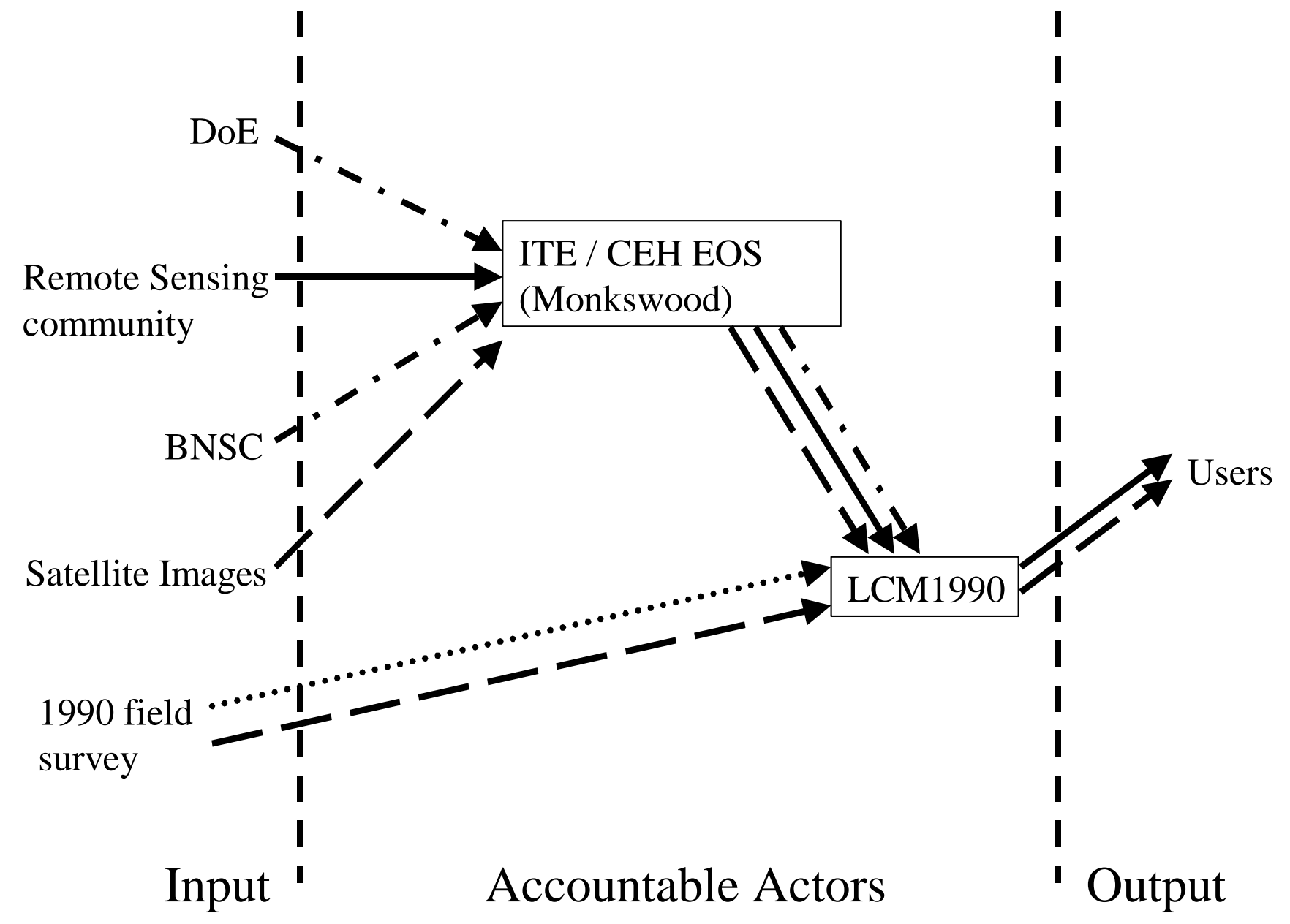

Fig 1 


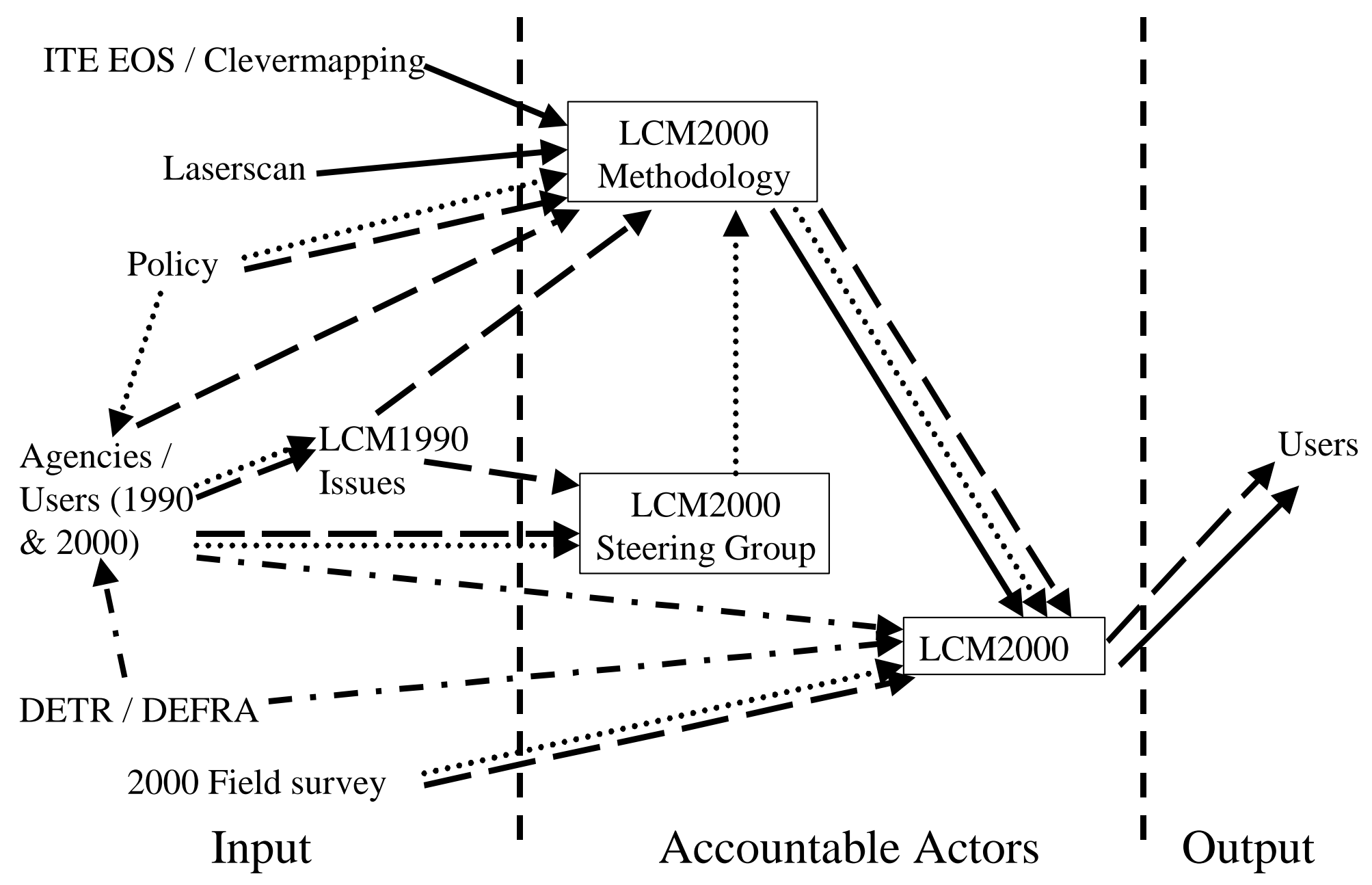

Fig 2 


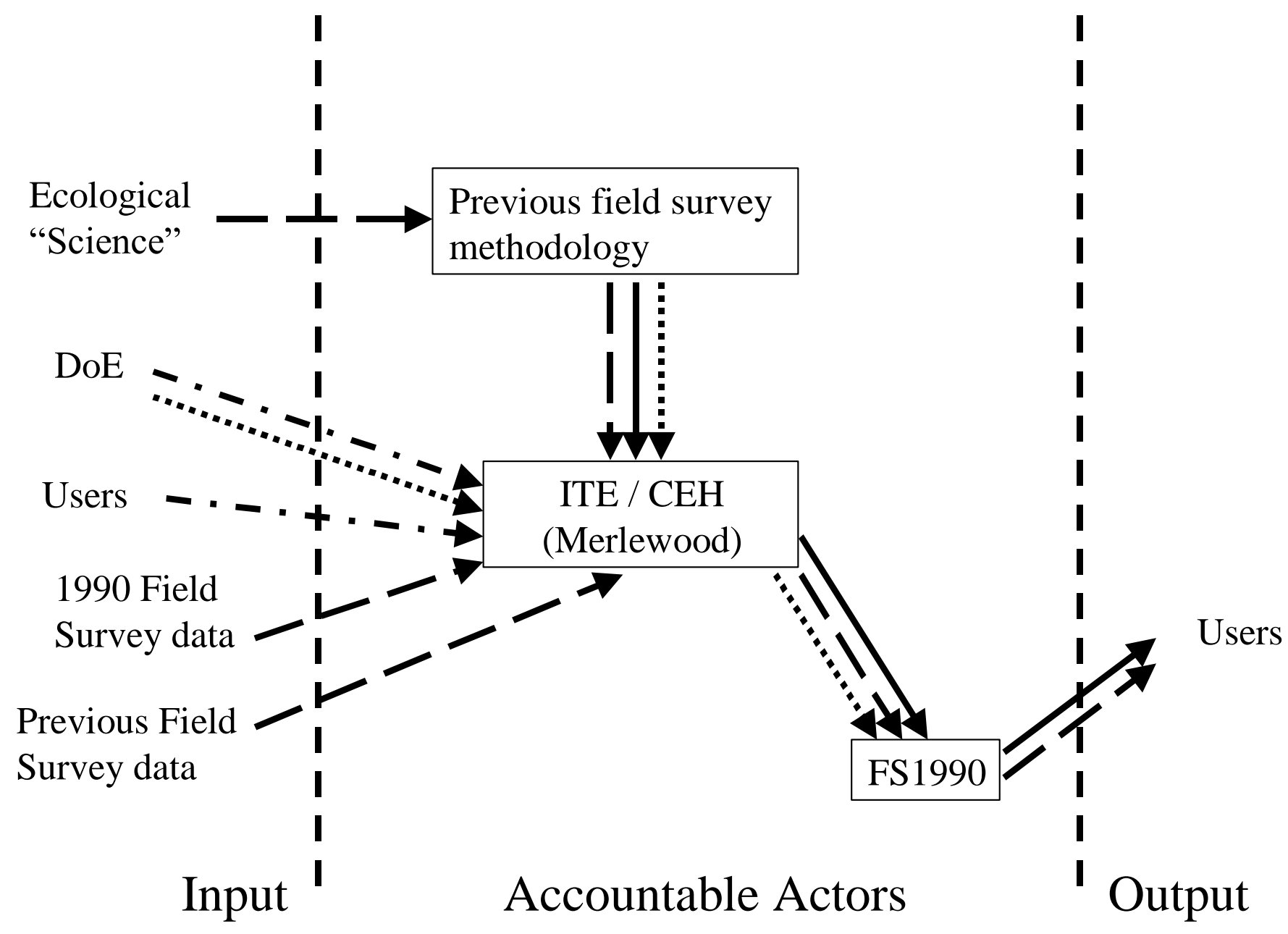

Fig 3 


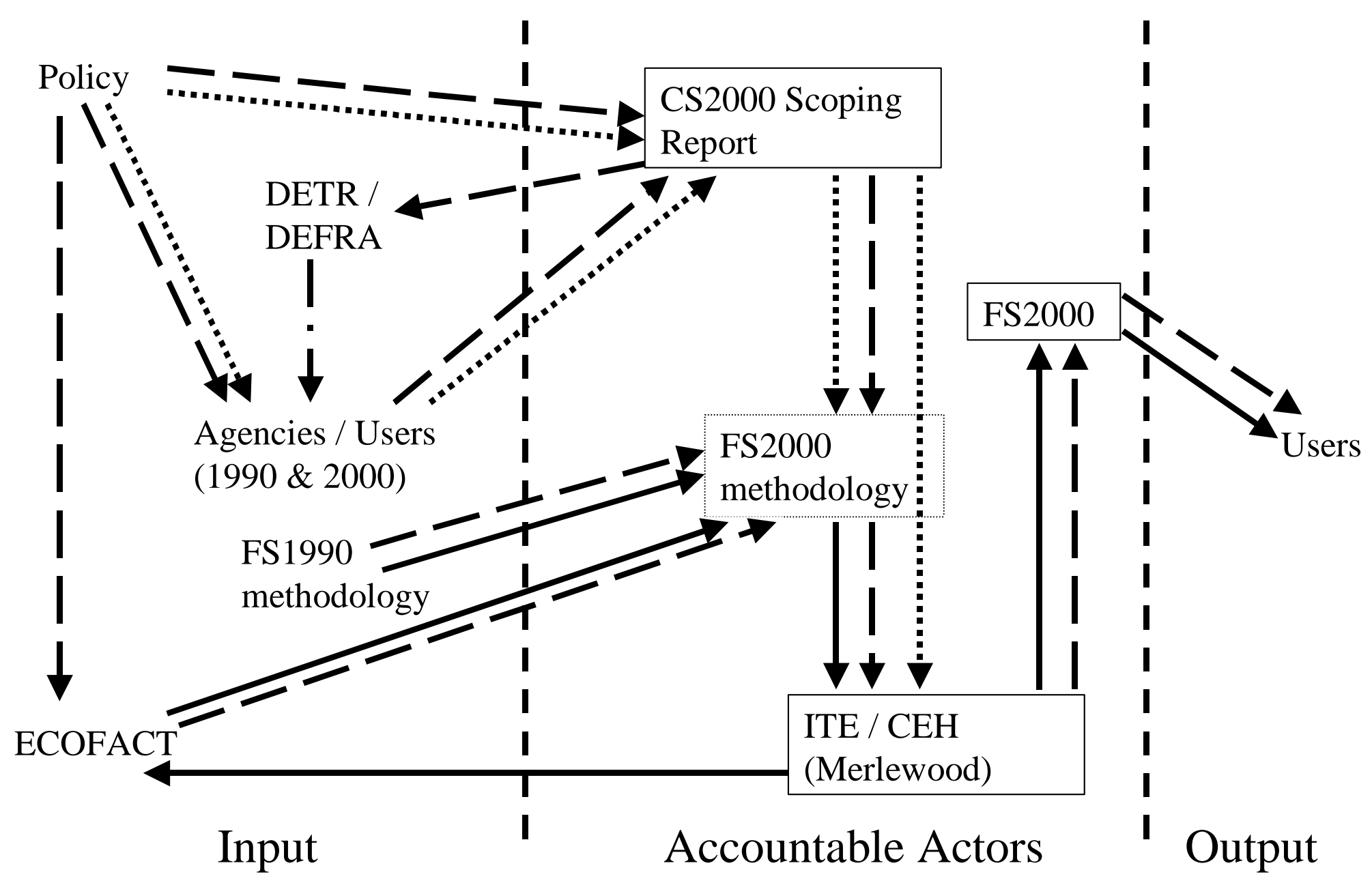

Fig 4 